Fournal of Medical Genetics (1975). 12, 294-298.

\section{Haemoglobin Hasharon in a north Italian community}

Summary. A survey of haemoglobin variants undertaken in an Italian community (Polesine) has revealed the presence of haemoglobin Hasharon $\left(\alpha_{2} 47\right.$ Asp $\rightarrow$ His $\beta_{2}$ ) in 108 subjects from 40 families.

The variant accounted for 30 to $40 \%$ of the total haemoglobin. In subjects doubly heterozygous for $\mathrm{Hb}$ Hasharon and $\beta$ thalassaemia, the proportion was 17 to $19 \%$. Though there was some evidence that the variant was unstable in vitro, there was no obvious haemoglobinopathy in vivo.

Haemoglobin Hasharon is an abnormal haemoglobin in which the aspartic acid residue normally present at position 47 of the $\alpha$ chain is replaced by histidine. This variant has been found in Hebrew families of Ashkenazi origin in Israel and the USA (de Vries et al, 1963; Halbrecht et al, 1967; Schneider et al, 1968; Charache et al, 1969).

In this paper we report the findings of this variant in 108 subjects belonging to 40 unrelated families, living in Polesine (Italy) in the province of Rovigo. In this area where the $\beta$-thalassaemia trait is very frequent $(10 \%)$, we have found $\mathrm{Hb}$ Hasharon in about $0.80 \%$ of the population.

No carrier of Hasharon trait remembered having Jewish antecedents hence we cannot exclude the possibility of a spontaneous mutation. However, at the end of the 15th century, Ashkenazi Jews driven away from cities of northern Italy, emigrated to this area, where the social and economical development, in proximity of the Adriatic sea, was for many years affected by the flooding of the Po river and by malaria.

Received 4 October 1974.
These conditions isolated this population and possibly favoured an increase in frequency of the $\beta$ thalassaemia trait and perhaps also of the $\mathrm{Hb}$ Hasharon trait. This increase in frequency may also have been effected by endogamy.

\section{Materials and methods}

Blood from 5000 subjects (school children, blood donors, and hospital patients) was screened for $\beta$ thalassaemia. Haemoglobin was extracted by both the waterether and water-carbontetrachloride methods and horizontal electrophoresis of haemoglobin was performed on cellulose-acetate strip with Tris buffer, $\mathrm{pH} 9.5$ (Graham and Grunbaum, 1963). Stability was tested by the isopropanol treatment, $\mathrm{pH}$ 7.4, of Carrell and Kay (1972) and incubation at $50^{\circ} \mathrm{C}$ for $2 \mathrm{~h}$ (method of Jacob and Winterhalter, 1970).

The abnormal haemoglobin was characterized in $\mathbf{4 0}$ specimens (one specimen from each family) by separation of globin chains on cellulose acetate (Komarmy ando Barnes, 1972) and by hybridization with canine haemoglobin (Huehns et al, 1962). Globin was prepared by the method of Rossi-Fanelli et al (1958), separation of the polypeptide chains and tryptic digestion was carried out as described by Clegg et al (1966), the fingerprints were obtained according to the method of Ingram (1958) as modified by Baglioni (1961). The peptide spots were visualized with ninhydrin $(0.2 \% \mathrm{~W} / \mathrm{V}$ in acetone) and stained with specific reagents for tyrosine and histidine (Easley, 1965).

The peptides to be analysed were eluted directly from ninhydrin-stained fingerprints, with $\mathrm{HCl}$ and hydrolysis was carried out under vacuum for $18 \mathrm{~h}$ at $105^{\circ} \mathrm{C}$.

The amino-acid composition of the hydrolysates was determined by the method of Spackman et al (1958).

\section{Results}

Of the 5000 specimens examined, 108 had an abnormal haemoglobin electrophoretic pattern, with a slow moving haemoglobin variant of the mobility of $\mathrm{Hb} \mathrm{S}$, but with two $\mathrm{Hb} \mathrm{A}_{2}$ fractions, indicating the presence of an $\alpha$-chain variant (Fig. 1). Hybridization with canine haemoglobin as well as the separation of the dissociated polypeptide chains on cellulose-acetate electrophoresis confirmed that the charge difference was indeed in the $\alpha$ chain. 


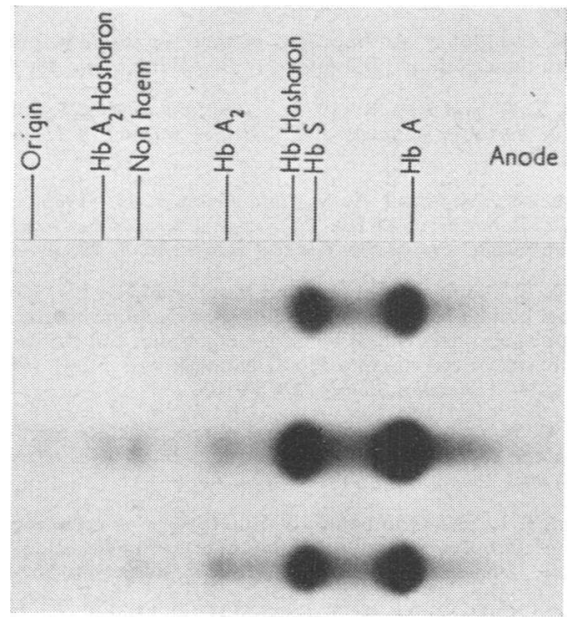

Fig. 1. Electrophoresis on cellulose acetate, pH 9.6. Hb S trait (top and bottom) and $\mathrm{Hb}$ Hasharon trait (middle); two fractions $\mathrm{Hb} \mathrm{A}_{2}$ are visible.

On CM cellulose column chromatography the abnormal $\alpha$ chain was eluted after the normal $\alpha$ chain (Fig. 2).

In all 40 families the fingerprint pattern (Fig. 3) of the purified abnormal $\alpha$ chain revealed the absence of the spot for $\alpha \mathrm{TpVI}$ (containing residues $41-56$ and giving positive reaction for histidine and tyrosine) and the appearance of a new spot with a more cathodal mobility than normal $\alpha \mathrm{TpVI}$ and giving positive reactions for histidine and tyrosine. The amino-acid composition of the new peptide was similar to that of $\alpha \mathrm{TpVI}$ except for the absence of aspartic acid and the presence of three histidine residues instead of two, thus suggesting that aspartic acid $\alpha 47$ has been replaced by histidine (Table I). This substitution is characteritic of the Hb Hasharon (Halbrecht et al, 1967) known as Hb Beilinson (de Vries et al, 1963), Hb Sinai (Charache et al, 1969), and $\mathrm{Hb}$ Sealy (Schneider et al, 1968). In our subjects the concentration of the haemoglobin variant was

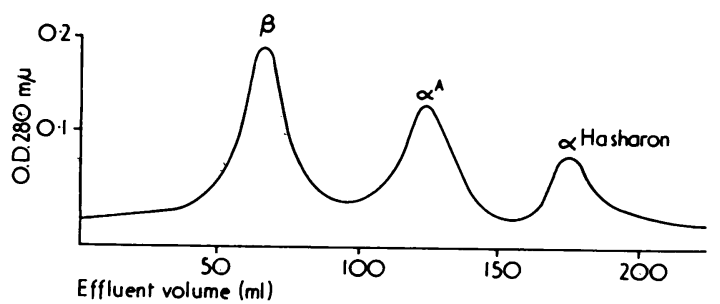

FIG. 2. CM cellulose chromatography of the globin chain.

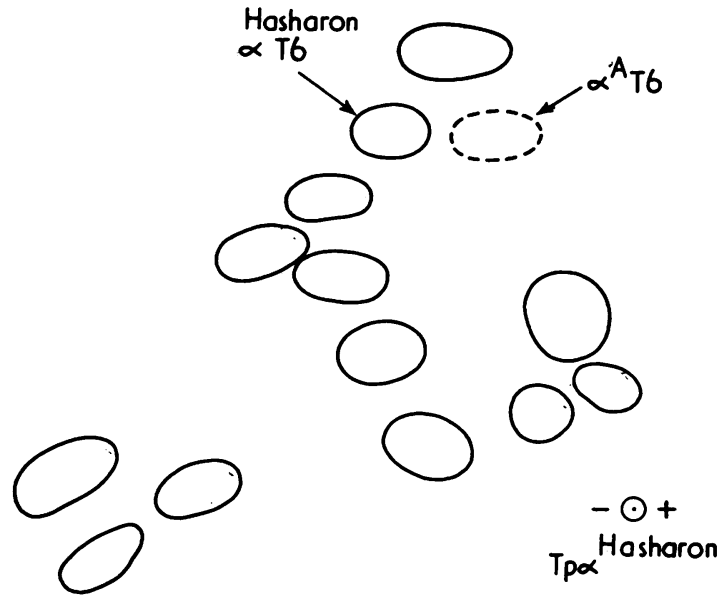

Fig. 3. Fingerprint of the $\alpha$ chain of Hb Hasharon.

TABLE I

AMINO-ACID COMPOSITION OF $\alpha^{\mathrm{A}}$ TpVI AND $\alpha^{\mathrm{H}}$ TpVI

\begin{tabular}{c|c|c}
\hline \multirow{2}{*}{$\begin{array}{c}\text { Amino } \\
\text { Acid }\end{array}$} & \multicolumn{2}{|c}{ Molar Ratio } \\
\cline { 2 - 3 } & $\alpha^{\mathrm{A}}$ TpVI & $\alpha^{\mathrm{H}}$ TpVI \\
\hline Lys & 0.90 & 1.10 \\
His & 1.90 & 3.22 \\
Asp & 1.02 & 0.00 \\
Thr & 0.93 & 0.89 \\
Ser & 2.10 & 1.90 \\
Glu & 1.02 & 0.99 \\
Pro & 1.10 & 1.17 \\
Gly & 1.04 & 1.10 \\
Ala & 1.04 & 1.06 \\
Val & 1.22 & 1.04 \\
Leu & 1.14 & 1.02 \\
Tyr & 0.83 & 0.80 \\
Phe & 1.97 & 1.94 \\
\hline
\end{tabular}

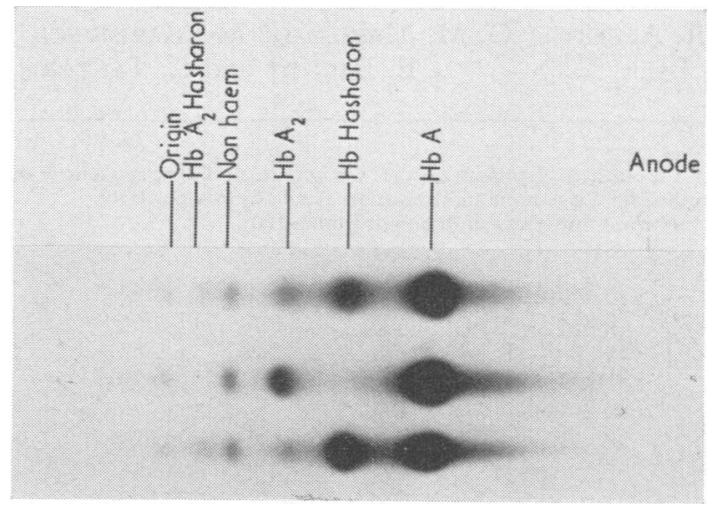

FIG. 4. Electrophoresis of double heterozygosity $\beta$-thalassaemia trait in one family. Top: Hb Hasharon (mother). This shows the impressive lowering of $\mathrm{Hb}$ Hasharon concentration when associated with $\beta$-thalassaemia trait. Middle: $\beta$-thalassaemia trait (son) Bottom: Hasharon trait (son). 
$30-40 \%$ of the total haemoglobin, which is higher than that found by Charache et al (1969). In six families 14 carriers, heterozygous for $\beta$ thalassaemia and $\mathrm{Hb}$ Hasharon, showed a concentration of the variant between $17-19 \%$ (Fig. 4).

Laboratory, haematological, and clinical findings. On supravital staining no inclusion bodies (Heinz bodies) were observed. However, the lability test for unstable haemoglobin was positive in each of the cases. The amount of the precipitated material was proportional to that of the $\mathrm{Hb}$ Hasharon present. The majority of $\mathrm{Hb}$ Hasharon carriers were not anaemic; red cell counts, haemoglobin levels, $\mathrm{MCH}$ and $\mathrm{MCV}$ were all normal. There was no evidence of haemolysis. Only six of the subjects show a decreased osmotic fragility with mild degree of morphological changes of the red cells and an increase of the reticulocyte count $(2.4 \%)$ without evident signs of haemolysis as in the case cited by Charache et al (1969).

The findings in the 14 carriers doubly affected ( $\mathrm{Hb}$ Hasharon and $\beta$-thalassaemia trait) was a moderate microcytosis, and poikilocytosis with hypochromia. The saline osmotic fragility was invariably reduced. The findings suggested a mild well compensated anaemia. The total and indirect levels of serum bilirubin were the same as in the normal relatives except for three subjects with a moderate increase of indirect bilirubin.

The authors wish to express their sincere gratitude for valiant assistance to the following technicians: $\mathrm{Mr}$ Pecci Giulio of the Istituto Superiore Sanità (Rome) and $\mathbf{M r}$ Bellinello Fausto, Miss Bedendo Bruna, and Miss Mercuriati Maria of the Centro Studi sulla Talassemia, Ospedale Civile di Rovigo.

\section{R. Alberti,* G. M. MariUzzi,* M. Marinucci, $\dagger$ E. BRUNI, $†$ and L. TENTORI $\dagger$}

\footnotetext{
- Cattedra di Istochimica dell'Università di Ferrara, Centro di Studi sulla Talassemia dell'Ospedale Civile di Rovigo, Italy. † Istituto Superiore di Sanità di Roma, Italy.
}

\section{REPERENCES}

Baglioni, C. (1961). An improved method for the fingerprinting of human hemoglobin. Biochimica et Biophysica Acta, 48, 392-396.

Carrell, R. W. and Kay, R. (1972). A simple method for the detection of unstable haemoglobins. British fournal of Haematology, 23, 615-619.

Charache, S., Mondzac, A. M., and Gessner, U. (1969). Hemoglobin Hasharon $\left(\alpha_{2} 47 \mathrm{His}(\mathrm{CD} 5) \beta_{2}\right)$ : a hemoglobin found in low concentration. Fournal of Clinical Investigation, 48, 834-847.

Clegg, J. B., Naughton, M. A., and Weatherall, D. J. (1966). Abnormal human haemoglobins. Separation and characterization of the alpha and beta chains by chromatography, and the determination of two new variants $\mathrm{Hb}$ Chesapeak and $\mathrm{Hb} \mathrm{J}$ (Bangkok). fournal of Molecular Biology, 19, 91-108.

Easley, C. W. (1965). Combinations of specific color reactions useful in the peptide mapping technique. Biochimica et Biophysica Acta, 107, 386-388.

Graham, J. L. and Grunbaum, B. W. (1963). A rapid method for microelectrophoresis and quantitation of hemoglobins on cellulose acetate. American fournal of Clinical Pathology, 39, 567-578.

Halbrecht, I., Isaacs, W. A., Lehmann, H., and Ben-Porat, F. (1967). Hemoglobin Hasharon (alpha 47 aspartic acid $\rightarrow$ histidine). Israel fournal of Medical Sciences, 3 (6), 827-831.

Huehns, E. R., Shooter, E. M., and Beaven, G. H. (1962). On recombination of canine and human haemoglobins. Fournal of Molecular Biology, 4, 323-328.

Ingram, V. M. (1958). Abnormal human haemoglobins. I. The comparison of normal human and SICKLE-cell haemoglobins by 'fingerprinting'. Biochimica et Biophysica Acta, 28, 539-545.

Jacob, H. S. and Winterhalter, K. H. (1970). The role of hemoglobin heme loss in Heinz body formation: studies with a partially heme-deficient hemoglobin and with genetically unstable hemo globins. Fournal of Clinical Investigation, 49, 2008-2016.

Komarmy, L. and Barnes, M. G. (1972). Separation of globin chains by rapid cellulose acetate electrophoresis. American fout nal of Clinical Pathology, 58, 428-430.

Rossi-Fanelli, A., Antonini, E., and Caputo, A. (1958). Studies on the structure of hemoglobin. I. Physicochemical properties of human globin. Biochimica et Biophysica Acta, 30, 608-615.

Schneider, R. G., Ueda, S., Alperin, J. B., Brimhall, B., and Jones, R. T. (1968). Hemoglobin Sealy (alpha $247 \mathrm{His}$ beta $_{2}$ ): a new variant in a Jewish family. American fournal of Medical Genetics, 20, 151-156.

Spackman, D. H., Stein, W. H., and Moore, S. (1958). Automatic recording apparatus for use in the chromatography of amino acids. Analytical Biochemistry, 30, 1190-1206.

Vries, A. de, Joshua, H., Lehmann, H., Hill, R. L., and Fellows, R. E. (1963). The first observation of an abnormal haemoglobin in a Jewish family: haemoglobin Beilinson. British fournal of Haematology, 9, 484-486. 